GORD

\section{Gastro-oesophageal reflux disease: symptoms, erosions, and Barrett's- what is the interplay?}

\section{P Sharma}

\section{The presence of Barrett's oesophagus may exert a negative impact} on healing of erosive oesophagitis in gastro-oesophageal reflux disease

$\mathrm{T}$ he outcomes of patients with erosive oesophagitis, treated with acid suppression therapy (proton pump inhibitors), has been dictated by the baseline severity of erosive oesophagitis, presence of hiatus hernia, duration of therapy and, in some studies, by the Helicobacter pylori status of the patients. ${ }^{12}$ It has been shown that higher grades of erosive oesophagitis (Los Angeles grades $\mathrm{C}$ and D) have significantly lower healing rates as opposed to those with lower grades of erosive oesophagitis (grades A and B). Moreover, the majority of the oesophagitis trials have evaluated healing at four and eight weeks, showing a higher proportion of patients with all grades of erosive oesophagitis healed at week 8 compared with week $4 .^{3}$ Similar data on healing at $>8$ weeks are not consistently available in the literature. Not only do patients with severe grades of erosive oesophagitis have a higher degree of oesophageal acid exposure compared with those with either no oesophagitis or low grades of oesophagitis, but they also have low amplitude of oesophageal contractions and the presence of large hiatus hernias. ${ }^{5}$ Therefore, it is not surprising that the poor pathophysiology associated with severe erosive oesophagitis leads to poor healing rates. Although a few studies have correlated $H$ pylori status with oesophagitis healing, with $H$ pylori positivity associated with improved healing rates, this has not been consistently documented. ${ }^{6}$ This may be a phenomenon related not just to the presence or absence of $H$ pylori infection but rather to the pattern of gastritis, presence of hiatus hernia, acid output states, etc. ${ }^{2}$ Although patients with Barrett's oesophagus also have abnormal pathophysiology, very similar to patients with severe grades of erosive oesophagitis, the impact of the presence of Barrett's oesophagus in patients with erosive oesophagitis has not been systematically evaluated. In fact, previous trials of erosive oesophagitis have excluded patients with Barrett's oesophagus and therefore the effect of healing of erosive oesophagitis in the presence of Barrett's oesophagus is not known.

In this issue of $G u t$, Malfertheiner and colleagues ${ }^{7}$ report results from the Progression of gastro-oesophageal reflux disease (ProGORD) trial, a large, multicentre, prospective, follow up study of 6215 patients with reflux disease treated with esomeprazole (open label) (see page 746). Results for heartburn resolution in patients with erosive oesophagitis and non-erosive reflux disease (NERD) were presented for the last visit and the prognostic influence of the baseline grade of erosive oesophagitis, presence of Barrett's oesophagus, age, sex, body mass index, and $H$ pylori infection was studied on the healing of erosive oesophagitis and, for NERD patients, on complete resolution of heartburn. Barrett's oesophagus was detected in $14 \%$ of patients with erosive oesophagitis and in $2.3 \%$ of NERD patients. The overall healing rates of erosive oesophagitis at eight weeks in all patients (with and without Barrett's oesophagus) was $77.5 \%$; $79.3 \%$ in grades A and B compared with $69.9 \%$ in grades $\mathrm{C}$ and $\mathrm{D}(\mathrm{p}<0.0001)$. In patients without Barrett's oesophagus, the healing rate of oesophagitis was $79.3 \%$ compared with $66.7 \%$ in those with Barrett's $(p<0.0001)$. These eight week healing rates in patients with Barrett's oesophagus were also directly related to baseline oesophagitis severity $(78.6 \%$ in grades A and $\mathrm{B} ; 63 \%$ in grades $\mathrm{C}$ and $\mathrm{D})$. Healing rates were lower in those with "confirmed Barrett's oesophagus" (with histological documentation of intestinal metaplasia) and also those with endoscopic Barrett's oesophagus (that is, oesophageal columnar segment). Whereas the presence of severe grades of erosive oesophagitis (that is, C and D) have been shown to influence healing of erosive oesophagitis, this is one of the initial reports to show the presence of Barrett's oesophagus as having a negative impact on healing of erosive oesophagitis.

Systematic biopsies were not obtained from the oesophageal columnar segment; the number of biopsies and endoscopic measurement of the length of Barrett's oesophagus were also not standardised between participating centres. Although all endoscopists were trained on the LA classification system for erosive oesophagitis, the diagnosis of Barrett's oesophagus was performed without any predetermined criteria. Furthermore, obtaining biopsies from the oesophagus were left up to the discretion of the endoscopists; additional biopsies were requested but were not mandatory from the endoscopists. It is well known that there is large interobserver variability in the endoscopic recognition of the oesophageal columnar segment and that detection of intestinal metaplasia is directly related to the endoscopy/biopsy technique and number of biopsies obtained. ${ }^{8} 9$ Moreover, it is possible that patients with higher grades of erosive oesophagitis (grades $\mathrm{C}$ and D) may be more likely to have been included in the "Barrett's group" as inflammatory lesions might have been mistaken as columnar areas in the distal oesophagus.

Complete symptom resolution, as determined by a validated reflux disease questionnaire, was $58.5 \%$ at two weeks and $64.8 \%$ at the last visit in the NERD group compared with $61.1 \%$ and $70.4 \%$, respectively, in the oesophagitis group. Thus the absolute difference in patients with heartburn resolution between the oesophagitis and NERD groups at the last visit was $5.6 \%$, suggesting that these are relatively similar patient groups in terms of both pathophysiology and treatment response. These data however do not reflect the same point in time in each group and although the comparison is not ideal, this highlights the fact that complete symptom resolution is difficult to achieve. Symptom resolution (measured by validated questionnaires) can be achieved in approximately $60-75 \%$ of GORD patients treated with proton pump inhibitor therapy and although the numbers may be numerically higher in patients with erosive oesophagitis, they are still nowhere closer to healing rates, suggesting that symptoms are more resistant to acid suppression than mucosal breaks (that is, erosions). ${ }^{10}$ On the other hand, it is not clear if patients actually seek complete symptom resolution and maybe goals such as complete resolution of symptoms as evaluated in this and other 
trials should not be the primary end point of treatment.

This study highlights some important issues; firstly, symptoms, erosions, and Barrett's can coexist in every possible combination in a patient with GORD, indicating that these are not independent lesions; secondly, the presence of Barrett's mucosa exerts a negative impact on the healing of erosive oesophagitis; and finally, that symptom resolution is difficult to achieve in GORD patients (with or without erosive oesophagitis). What are the clinical implications of these findings? This study raises questions regarding the need for higher doses of proton pump inhibitors or more profound acid suppression in patients with Barrett's oesophagus. Whether persistent oesophagitis and ongoing inflammation in patients with Barrett's oesophagus can lead to a higher frequency of dysplasia and adenocarcinoma remains to be evaluated and, if this is the case, may have important chemopreventative ramifications. Symptoms appear to be a poor marker for healing of erosive oesophagitis in patients with Barrett's oesophagus, and therefore for assessing healing repeat endoscopy may be considered in this subgroup of patients. Present drug therapy is unable to resolve symptoms or heal oesophagitis completely for this complex disease, and the role of other factors such as nonacid or low acid reflux, bile reflux, oesophageal hypersensitivity, or central mechanisms which lead to persistent symptoms, should be evaluated further. Despite the major progress in our understanding of the diagnosis and treatment of GORD, this study highlights the need for continued investigation of this intriguing disease.

Gut 2005;54:739-740.

doi: $10.1136 /$ gut.2004.052225

Correspondence to: Professor P Sharma, University of Kansas School of Medicine, VA Medical Center, Kansas City, MO 64128, USA; psharma@kumc.edu

Conflict of interest: None declared.

\section{REFERENCES}

1 Kahrilas PJ, Falk GW, Johnson DA, et al. Esomeprazole improves healing and symptom resolution as compared with omeprazole in reflux oesophagitis patients: a randomized controlled trial. Aliment Pharmacol Ther 2000; 14: 1249-58.
2 Sharma P, Vakil N. Helicobacter pylori and reflux disease. Aliment Pharmacol Ther 2003:17:297-305.

3 Castell DO, Kahrilas PJ, Richter JE, et al. Esomeprazole $(40 \mathrm{mg})$ compared with lansoprazole $(30 \mathrm{mg})$ in the treatment of erosive esophagitis. Am J Gastroenterol 2002;97:575-83.

4 Richter JE, Kahrilas PJ, Sontog SJ, et al. Comparing lansoprazole and omeprazole in onset of heartburn relief: results of a randomized, controlled trial in erosive esophagitis patients. Am J Gastroenterol 2001;96:3089-98.

5 Coenraad M, Masclee AA, Straathof JW, et al. Is Barreftt's esophagus characterized by more pronounced acid reflux than severe esophagitis? Am J Gastroenterol 1998;93:1068-72.

6 Holtmann G, Cain C, Malfertheiner P. Gastric Helicobacter pylori infection accelerates healing of reflux esophagitis during treatment with the proton pump inhibitor pantoprazole. Gastroenterology 1999:117:11-16.

7 Malfertheiner P, Lind T, Willich S, et al. Prognostic influence of Barrett's oesophagus and Helicobacter pylori infection on healing of erosive gastro-oesophageal reflux disease (GORD) and symptom resolution in non-erosive GORD: report from the ProGORD study. Gut 2005;54:746-51.

8 Sharma P, Morales TG, Sampliner RE. Short segment Barrett's esophagus - the need for standardization of the definition and of endoscopic criteria. Am J Gastroenterol 1998:93:1033-6.

$9 \operatorname{Kim} \mathrm{R}$, Baggott BB, Rose S, et al. Quantitative endoscopy: precise computerized measurement of metaplas epithelial surface area in Barrett's esophagus. Gastroenterology 1995; 108:360-6.

10 Pace F, Bianchi Porro G. Gastroesophageal reflux disease: A typical spectrum disease (A new conceptual framework is not needed) Am J Gastroenterol 2004;99:946-9.

\section{Screening for early gastric cancer}

\section{K E L McColl}

\section{Can serological testing for Helicobacter pylori infection and atrophic gastritis predict the risk of gastric cancer?}

G astric cancer remains one of the most common malignancies in the world. ${ }^{1}$ The great majority of cases are fatal because the tumour has usually reached an incurable stage by the time of diagnosis. ${ }^{2}$ The early potentially curable stage of the disease is usually asymptomatic and consequently patients mainly present when they have developed symptoms of advanced or complicated disease. ${ }^{2} 3$ There is considerable interest in a means of detecting this common cancer at an early and curable stage.

In the Western world, the incidence of gastric cancer distal to the cardia has fallen over recent decades whereas that at the cardia and gastro-oesophageal junction has increased markedly. ${ }^{4}$ However, at a global level, non-cardia gastric cancer remains the predominant type and it is this which we are discussing. ${ }^{1}$

Major advances have been made in our understanding of the aetiology and pathogenesis of non-cardia gastric cancer and of the precancerous changes which occur in the gastric mucosa. Helicobacter pylori infection is now accepted as an essential cofactor in the majority of cases of non-cardia gastric cancer. ${ }^{5}$ However, detecting the presence of the infection is, in itself, of limited value in predicting cancer occurrence; more than $50 \%$ of the world's population have the infection and the lifetime risk of an infected individual developing the cancer is less than $2 \%$.

Recent studies have indicated that the risk of a person with $H$ pylori infection developing non-cardia gastric cancer is highly dependent on the pattern of gastritis and altered physiology which the infection induces in their stomach. ${ }^{6}$ In some patients, the infection induces an antral predominant non-atrophic gastritis associated with normal or high acid secretion. Patients with this gastric phenotype may develop duodenal ulcers but very rarely develop gastric cancer. Other patients develop an atrophic pangastritis and reduced gastric acid secretion and it is this gastric phenotype which is associated with gastric cancer. These two phenotypes represent ends of a spectrum, with many subjects showing an intermediate disease pattern. It is also possible for patients to progress from the non-atrophic to atrophic pattern with advancing years. ${ }^{78}$

In a large prospective study in Japan, Uemura et al endoscopically monitored patients with $H$ pylori infection and different gastric phenotypes for a mean of 7.8 years. ${ }^{6}$ None of the duodenal ulcer patients developed gastric cancer. However, $4.7 \%$ of non-ulcer dyspepsia patients developed cancer and its occurrence was strongly associated with the presence of atrophic pangastritis detected at the initial endoscopy. Such observations have stimulated interest in using the $H$ pylori induced gastric phenotype to direct screening for early gastric cancer.

$H$ pylori infection can be diagnosed nonendoscopically by means of serology. 
It is also possible to detect atrophic gastritis serologically. The concentration of pepsinogen $\mathrm{I}$ and the ratio of pepsinogen I/II are low in patients with atrophic gastritis. ${ }^{9}{ }^{10}$ Consequently, simple blood tests can determine whether a subject has $H$ pylori infection and whether the infection has induced the atrophic pattern of gastritis which is associated with a high risk of gastric cancer.

In this issue of Gut, Watabe and colleagues $^{11}$ present a large prospective study in which they have assessed the value of combined serological testing for $H$ pylori infection and atrophic gastritis in predicting the risk of gastric cancer (see page 764). The study included almost 10000 members of the general population who had annual endoscopic examinations for a mean of five years following serological tests. They analysed the outcome by dividing subjects into four groups according to whether they were $H$ pylori seropositive or negative and whether they had a low pepsinogen I and I/II ratio, indicating atrophic gastritis.

The risk of developing gastric cancer in $H$ pylori negative patients without atrophic gastritis was similar to that in $H$ pylori positive patients without atrophic gastritis. Relative to these two groups, the risk of cancer was sixfold higher in $H$ pylori positive patients with atrophic gastritis and eightfold higher in $H$ pylori negative patients with atrophic gastritis. Age and male sex were also independent risk factors for cancer occurrence.

This study provides useful confirmation of the importance of the gastric phenotype induced by $H$ pylori infection in determining the risk of gastric cancer. Patients with $H$ pylori infection but no evidence of atrophy had a similar cancer risk to those with an uninfected healthy stomach, at least over the subsequent five years examined in this study. Patients with atrophic gastritis had a markedly increased cancer risk irrespective of $H$ pylori serology. Atrophy in those with negative $H$ pylori serology can be largely explained by the tendency for the infection to disappear in the atrophic achlorhydric stomach. ${ }^{12}$ Due to this phenomenon, one can conclude that $H$ pylori serology on its own is of limited value in determining the risk of imminent development of gastric cancer and that detecting atrophic gastritis by serum pepsinogens is the important test.

How useful would such serological testing be in identifying the subgroup of the population most likely to develop cancer within the subsequent five years and who might benefit from careful surveillance endoscopy? The data presented by Watabe and colleagues ${ }^{11}$ indicate that serological screening for low pepsinogen I would allow identification of a subgroup of $22 \%$ of the population who would go on to develop $70 \%$ of the gastric cancers occurring within the following five years. The annual incidence of cancer in subjects in the high risk groups in this Japanese based study was approximately $0.5 \%$ and thus equivalent to the risk of cancer occurrence in Barrett's oesophagus patients studied in the West. ${ }^{13}$

Identifying subjects at high and imminent risk of developing gastric cancer is only useful if one can intervene to improve the natural history of the disease. Such intervention at present involves annual endoscopies to detect and treat the tumours at an early stage of their development. In this study reported by Watabe and colleagues," such a strategy allowed them to detect all of the cancers which developed in the high risk groups while still localised within the submucosa. Approximately $50 \%$ of the tumours were treated by endoscopic resection and the remainder underwent surgical operation. The ability to detect early tumours endoscopically depends on adequate endoscopic facilities and operator skills. Although these are undoubtedly common place in Japan, they may not be so readily available in other countries with a persistent high incidence of gastric cancer. However, one great attraction of the pepsinogen serological screening is that it allows the available resources to be concentrated on the group most likely to benefit from them and so increases cost effectiveness.

Although the ability to detect gastric cancer at an early curable stage is attractive, it is not always in the individual's best interests. The natural history of early gastric cancer means that left untreated it usually does not cause clinical problems for several years and indeed may not cause any symptoms during the patient's natural lifespan. $^{14}{ }^{15}$ Surgical gastric resection is associated with morbidity and a small mortality. Although endoscopic resection is likely to be associated with less morbidity and mortality, the efficacy of this less radical management in achieving long term cure is less clear. Screening and surveillance for early gastric cancers would be more attractive if we had a simple, safe, and effective way of managing them.

The ideal way to reduce the mortality due to gastric cancer is to interrupt the precancerous process before an actual cancer develops. Prevention is better than cure. Current understanding is that $H$ pylori infection is usually an essential cofactor in initiating the sequence of events that finally lead to the cancer. ${ }^{16}$ One would therefore anticipate that preventing people contracting the infection in the first place or treating the infection at an early stage before irreversible atrophic gastritis develops would be the most effective and cost effective way of reducing the incidence of gastric cancer. Japan and other countries with a persistent high incidence of non-cardia cancer would be particularly appropriate for such a prophylactic interventional strategy.

However, even if every $H$ pylori infected subject in the world had their infection eradicated today, the incidence of gastric cancer would probably remain high for several decades to come. This is due to the fact that eradicating the infection does not produce resolution of atrophic gastritis and subjects with these irreversible changes will continue to be at risk of gastric cancer. Consequently, there will continue to be a need for more efficient ways of identifying subjects at high and imminent risk of developing this sinister tumour.

Gut 2005;54:740-742.

doi: $10.1136 /$ gut.2004.058461

Correspondence to: Professor K E L McColl, Section of Medicine, Western Infirmary, 44 Church St, Glasgow, UK; k.e.l.mccoll@clinmed. gla.ac.uk

Conflict of interest: None declared.

\section{REFERENCES}

1 Parkn DM, Whelan SL, Ferlay J, et al. Cancer incidence in five continents, volume VIII. Lyon: IARC, 2002, Scientific Publications No 155.

2 Allum WH, Powell DJ, McConkey CC, et al. Gastric cancer: a 25 year review. Br J Surg 1989;76:535-40.

3 Maruyama M, Kimura K. Early gastric carcinoma presenting as dyspepsia. In: Healty V, Moncur P, eds. Dyspepsia: The clinical consequences. Oxford: Blackwell Science, 2000:175-86.

4 Devesa SS, Blot WJ, Fraumeni JF. Changing patterns in the incidence of esophageal and gastric carcinoma in the United States. Cancer 1998;83:2049-53

5 Webb PM, Law M, Varghese C, et al. Gastric cancer and Helicobacter pylori: a combined analysis of 12 case control studies nested within prospective cohorts. Gut 2001;49:347-53.

6 Uemura N, Okamoto S, Yamamoto S, et al. Helicobacter pylori infection and the development of gastric cancer. N Engl J Med 2001;345:784-9.

7 Villako K, Kekki M, Maaroos HI, et al. Chronic gastritis: progression of inflammation and atrophy in a six-year endoscopic follow-up of a random sample of 142 Estonian urban subjects. Scand J Gastroenterol 1991;26(suppl 186): 135-41.

8 Hackelsberger A, Gunthre T, Schultze V, et al. Role of aging in the expression of Helicobacter pylori gastritis in the antrum, corpus and cardia. Scand J Gastroenterol 1999;34:138-43.

9 Samloff IM, Varis K, lhamaki T, et al. Relationship among serum pepsinogen I, serum pepsinogen II and gastric mucosal histology. A study in relatives with pernicious anemia. Gastroenterology 1982;83:204-93.

10 Borch K, Axelsson CK, Halgreen H, et al. The ratio of pepsinogen $A$ to pepsinogen $C: A$ sensitivie test for atrophic gastritis. Scand J Gastroenterol 1989;24:870-6. 
11 Watabe H, Mitsushima T, Yamaji Y, et al. Predicting the development of gastric cancer from combining Helicobacter pylori antibodies and serum pepsinogen status: a prospective endoscopic cohort study. Gut 2005;54:764-8.

12 Kokkola A, Kosunen T, Puolakkainen P, et al. Spontaneous disappearance of Helicobacter pylori antibodies in patients with advanced atrophic corpus gastritis. APMIS 2003;iii:619-24.

13 Falk GW. Barrett's esophagus. Gastroenterology 2002;122:1569-91.

14 Tsukuma H, Oshima A, Narahara H, et al. Natural history of early gastric cancer: a non-concurrent, long term, follow up study. Gut 2000;47:618-21.
15 Ubukata H, Katano M, Tabuchi T. A case of untreated gastric cancer followed for 7 years. Gastrointest Endosc 2004;60:476-80.

16 Brenner H, Arndt V, Stegmaier C, et al. Is Helicobacter pylori infection a necessary condition for noncardia gastric cancer? Am J Epidemiol 2004; 159:252-8.

\section{ADIPONECTIN, AN ANTI- INFLAMMATORY MEMBER OF THE CIQ/TNF SUPERFAMILY}

\section{Creeping fat in Crohn's disease: travel- ling in a creeper lane of research?}

\section{A Schäffler, H Herfarth}

Identification of a distinct secretion pattern of adipocytokines from creeping fat in Crohn's disease and from mesenteric adipose tissue in chronic inflammatory bowel diseases (IBD) or mesenteric diseases can be considered as work in progress. Characterisation of visceral adipose tissue by its highly active secretory products may lead to the discovery of specific discrimination and activity markers in IBD and may provide future targets for drug therapy. In addition, the cellular compartment of macrophages residing within the mesenteric adipose tissue is becoming recognised as bearing pathophysiological relevance.

\section{DR BURRIL B CROHN AND THE CREEPING FAT}

The connective and adipose tissue changes observed in patients with Crohn's disease (CD) have received only little attention from pathologists, although fat hypertrophy, fat wrapping (fat creeping upon the bowel), and creeping fat have long been recognised by surgeons as a phenomenon suitable for delineating the extent of active disease. Dr Burril B Crohn himself, who gave his name to this chronic inflammatory bowel disease, initially described the changes in the appearance of the mesenteric adipose tissue as a characteristic symptom of the disease. ${ }^{1}$ Sheehan and colleagues $^{2}$ and others ${ }^{3}$ defined fat wrapping as present if more than $50 \%$ of the intestinal surface is covered by adipose tissue. Fat encroachment of the antimesenteric surface of the bowel displays a characteristic feature of CD, leading to complete enveloping of the antimesenteric surface and obliteration of the bowel-mesentery angle. ${ }^{3}$

To date, the pathophysiology of creeping fat has been investigated only sporadically $^{2-5}$ and it seems to have fallen into oblivion. ${ }^{6}$

\section{WHY DOES ADIPOSE TISSUE MATTER?}

Adipose tissue has long been regarded as a passive type of connective tissue that stores energy as triglycerides and releases energy as free fatty acids. However, due to the wide variety of hormones, proteins, peptides, complement factors, cytokines, enzymes, and receptors expressed in and secreted by adipocytes, the total adipose tissue mass is currently being recognised as a real endocrine organ. ${ }^{7-11}$ Thus the term "adipocytokines"12 has been introduced for these highly active adipocyte derived cytokines, such as adiponectin, resistin, leptin, interleukin 6 (IL-6), tumour necrosis factor $\alpha(\mathrm{TNF}-\alpha)$, and many others. Macrophages infiltrating adipose tissue can transdifferentiate from local preadipocytes, ${ }^{13}$ suggesting the hypothesis that adipocytes and macrophages may be interconvertible. Charriere and colleagues $^{13}$ demonstrated that stromavascular cells from adipose tissue or 3T3-L1 preadipocytes can transdifferentiate to macrophages and acquire phagocytic activity. As these preadipocytes express macrophage specific antigens such as F4/80, Mac-1, CD80, CD86, and CD45, preadipocytes and macrophages may not be too different. ${ }^{14}$ The observation that adipocytes can function as macrophage-like cells by expressing and secreting molecules related to inflammation and innate immunity directly brings the mesenteric adipose tissue into the focus of mesenteric diseases.
Adiponectin, a new member of the Clq/ TNF molecular superfamily, ${ }^{15}$ is abundantly present in human sera and circulates as monomer, trimer, and high molecular weight forms. Apart from full length adiponectin, globular adiponectin is also biologically active. ${ }^{16}$ Recently, two adiponectin receptors, hAdipoRl and hAdipoR2, have been cloned. ${ }^{17}$ The signalling pathways are currently under investigation and phosphorylation of the insulin receptor, activation of the AMP activated protein kinase, activation of peroxisome proliferator activated receptor (PPAR) $\alpha$, and modulation of nuclear factor kappa B (NFKB) activity have been described as involved. ${ }^{18-20}$ Besides its metabolic effects in the context of hepatic insulin resistance, type 2 diabetes mellitus, atherosclerosis, and fatty liver, it mainly exerts antiinflammatory effects on macrophages and endothelial cells. Adiponectin can reduce secretion of TNF- $\alpha$ from monocyte/macrophages and attenuate the biological effects caused by TNF- $\alpha .^{21}$ Mice lacking adiponectin have high levels of TNF- $\alpha$ mRNA in adipose tissue, $^{22}$ and viral mediated delivery of adiponectin reverses the increase in adipose tissue TNF- $\alpha$ mRNA. In contrast with leptin, ${ }^{23}$ adiponectin prevents the attachment of monocytes to TNF- $\alpha$ stimulated endothelial cells ${ }^{24} 25$ through downregulation of intracellular adhesion molecule 1, extracellular adhesion molecule 1, and E-selectin. Therefore, adiponectin may inhibit the migration of monocytes to the mesenteric adipose tissue and suppress local TNF- $\alpha$ driven proinflammatory pathways.

\section{THE POTENTIAL ROLE OF ADIPONECTIN IN CROHN'S DISEASE}

In this issue of Gut, Yamamoto and colleagues $^{26}$ from the Osaka University School of Medicine, Japan, present an evaluation of adiponectin secretion from hypertrophied mesenteric adipose tissue of patients suffering from CD (see page 789).

They demonstrated that:

(1) tissue concentration and release of adiponectin (but not of IL-6) is significantly elevated in CD compared 
with patients suffering from ulcerative colitis (UC) or colon cancer,

(2) increased adiponectin secretion in CD is specifically related to inflamed and hypertrophied mesenteric adipose tissue (creeping fat) and not to normal adipose tissue in these patients, and

(3) hypertrophied adipose tissue in CD becomes infiltrated by large amounts of monocytes/macrophages.

While TNF- $\alpha$ inhibits adipogenesis by downregulation of $\mathrm{C} / \mathrm{EBP} \alpha, \operatorname{PPAR} \gamma,{ }^{27}{ }^{28}$ and macrophage colony stimulating factor (MCSF), ${ }^{29}$ activation of PPAR $\gamma$ by synthetic (glitazones) and endogenous ligands (15d-PG-J ${ }_{2}$ ) reduces TNF- $\alpha$ and leptin expression and increases adiponectin expression in adipocytes. ${ }^{30}$ In detail, PPAR $\gamma$ agonists inhibit the expression of proinflammatory cytokines such as IL- $1 \beta$, IL-2, IL-6, IL-8, monocyte chemoattractant protein (MCP-1), TNF- $\alpha$, and matrix metalloproteases by transcriptional regulation and interference with signalling pathways such as NFkB (p65, p50), AP-1 (fos/jun), mitogen activated protein kinase cascade, and STAT-1/STAT-3 $3^{31} 32$ in monocytes/macrophages, endothelial cells, smooth muscle cells, and adipocytes. These data could provide the potential mechanism of an anti-inflammatory action of PPAR $\gamma$ ligands in the context of IBD and creeping fat ${ }^{31}$ and could potentially be used for both reducing the release of proinflammatory cytokines and increasing the release of anti-inflammatory cytokines such as adiponectin from visceral adipose tissue. In the case of PPAR $\gamma$, recent data have pointed to this nuclear hormone receptor as a novel anti-inflammatory mediator with broad therapeutic potential in UC and $\mathrm{CD}^{33-35}$

\section{ADIPOCYTOKINES IN IBD: SECONDARY OR CAUSATIVE?}

Sheehan and colleagues ${ }^{2}$ and Smedh and colleagues ${ }^{4}$ interpreted fat wrapping solely as a consequence of transmural inflammation and thus as a chronic feature of the disease, probably caused by cytokine release from adjacent lymphoid tissues. ${ }^{2}$ Similarly, Borley and colleagues $^{5}$ interpreted the adipose tissue changes as related to the local effects of underlying chronic inflammatory infiltrates and released cytokines such as transforming growth factor $\beta 1$ and TNF- $\alpha$. Both cytokines have been discussed in relation to stimulating proliferation and activation of mesenchymal tissues. ${ }^{36-39}$ TNF- $\alpha$ and PPAR $\gamma$ mRNA expression is increased in mesenteric adipocytes contiguous with the involved intestine in patients with $\mathrm{CD}^{40}$ compared with adipocytes contiguous with healthy intestine or with controls.

However, specific overexpression of PPAR $\gamma,{ }^{40}$ adiponectin, TNF- $\alpha,{ }^{40}$ leptin, ${ }^{41}$ and $\mathrm{MCSF}^{42}$ in mesenteric adipocytes from patients with $\mathrm{CD}$ indicates that adipose tissue is an effector in the pathogenesis of CD. Taken together, mesenteric adipose tissue hypertrophy can be regarded as a cause of, or as a consequence of, intestinal inflammation in CD. The presence of mesenteric obesity at the onset of the disease, the axial polarity of inflammation, the association between connective tissue changes and transmural inflammation, and the release of highly active molecules from local adipocytes supports a more active role of adipose tissue in the pathogenesis of CD.

\section{VISCERAL ADIPOSE TISSUE MACROPHAGES: A NEW THERAPEUTIC TARGET?}

$\mathrm{Xu}$ and colleagues ${ }^{43}$ and Weisberg and colleagues $^{44}$ reported that adipose tissue becomes infiltrated by significant amounts of macrophages (but not lymphocytes or granulocytes) in the context of obesity. They also demonstrated that proinflammatory cytokines are produced mainly by adipose tissue homed macrophages rather than by adipocytes. It has been estimated that the

Table 1 The future potential of adiponectin and adipocytokines in gastroenterology

Chronic inflammatory bowel diseases

Activity markers, discrimination markers (UC-CD)

Crohn's disease

Pathophysiology of creeping fat, drug targets for transmural inflammation

Mesenteric panniculitis

Pathophysiology of mesenteric inflammation, targets for diagnosis and treatment

Pancreatitis

Pathophysiology of retroperitoneal fat necrosis, marker of prognosis, discrimination marker for necrotising verus oedematous pancreatitis

Gastrointestinal tumours

Markers of fat tissue infiltration (staging), diagnosis of peritoneal tumour spread

Liver cirrhosis

Discrimination between malignant versus benign ascites, discrimination between inflammatory versus non-inflammatory ascites

UC, ulcerative colitis; CD, Crohn's disease. percentage of macrophages in adipose tissue ranges from $<10 \%$ up to $>50 \%$, 44 suggesting a high cellular plasticity of adipose tissue. MCP-1 and macrophage inflammatory protein $1 \alpha$ have been demonstrated to be secreted with increasing amounts from adipose tissue in response to TNF- $\alpha^{43} 44$ and could therefore function as chemoattractants directing macrophage precursors into stores of fat tissue. ${ }^{45} 47$ Subsequently, a permissive microenvironment created by adipose tissue secretion of $\mathrm{MCSF}^{42}$ could lead to a continuing process of differentiation, transdifferentiation, and maturation of preadipocytic and nonpreadipocytic macrophage precursor cells. As the creeping fat in $C D$ is becoming infiltrated by a significant amount of macrophages, the cellular compartment of macrophages residing within the mesenteric adipose tissue is becoming recognised as bearing pathophysiological relevance in IBD.

\section{ADIPONECTIN AND ADIPOCYTOKINES IN \\ GASTROENTEROLOGY}

As adipose tissue hypertrophy is only seen in CD, secretory factors specifically expressed in adipose tissue could possibly serve as local or systemic activity markers for the disease or as discriminating markers for the diagnosis (for example, differential diagnosis between CD and UC). Release of highly active proinflammatory cytokines from fat cell necrosis in pancreatitis may explain the severe disease course. In addition, the pathophysiological role of adipocytokines in mesenteric panniculitis and gastrointestinal tumours (adipose tissue infiltration) has to be investigated. The future potential of adiponectin and adipocytokines in gastroenterological diseases is shown in table 1.

Gut 2005;54:742-744.

doi: 10.1136/gut.2004.061531

\section{Authors' affiliations}

A Schäffler, $\mathrm{H}$ Herfarth, Department of Internal Medicine I, University of Regensburg, Regensburg, Germany

Correspondence to: Dr A Schäffler, Department of Internal Medicine I, University of

Regensburg, D-93042 Regensburg, Germany; andreas.schaeffler@klinik.uni-regensburg.de

Conflict of interest: None declared.

\section{REFERENCES}

1 Crohn BB, Ginzburg L, Oppenheimer GD. Regional ileitis, a pathologic and clinical entity. $J$ Am Med Assoc 1932;99:1323-9.

2 Sheehan AL, Warren BF, Gear MWL, et al. Fatwrapping in Crohn's disease: pathological basis and relevance to surgical practice. Br J Surg 1992;79:955-8

3 Fazio VW. The surgery of Crohn's disease of the small bowel. In: Allan R, Keighley MRB, 
Alexander-Williams J, et al, eds. Inflammatory bowel diseases. Edinburgh: Churchill Livingstone, 1983:452-61.

4 Smedh K, Olaison G, Nyström PO, et al. Intraoperative enteroscopy in Crohn's disease. Br J Surg 1993;80:897-900.

5 Borley NR, Mortensen NJ, Jewell DP, et al. The relationship between inflammatory and serosal connective tissue changes in ileal Crohn's disease: evidence for a possible causative link. J Pathol 2000; 190: 196-2002

6 Colombel JF, Dubuquoy L, Sandborn WJ, et al. The adipose tissue as a source of proinflammatory signals in Crohn's disease? In: Herfarth $\mathrm{H}$, Feagan BG, Fölsch UR, et al, eds. Targets of treatment in chronic inflammatory bowel diseases. Dordrecht: Kluwer Academic Publishers, 2003:99-104.

7 Ahima RS, Flier JS. Adipose tissue as an endocrine organ. Trends Endocrinol Metab 2000;1 1:327-32.

8 Kershaw EE, Flier JS. Adipose tissue as an endocrine organ. J Clin Endocrinol Metab 2004;89:2548-56.

9 Rajala MW, Scherer PE. Minireview: The adipocyte - at the crossroads of energy homeostasis, inflammation, and atherosclerosis. Endocrinology 2003;144:3765-73.

10 Mohamed-Ali V, Pinkney JH, Coppack SW. Adipose tissue as an endocrine and paracrine organ. Int J Obes Relat Metab Disord 1998;22:1145-58.

11 Pantanetti P, Garrapa GG, Mantero F, et al. Adipose tissue as an endocrine organ? A review of recent data related to cardiovascular complications of endocrine dysfunctions. Clin Exp Hypertens 2004;26:387-98.

12 Shimomura I, Funahashi T, Takahashi $M$, et al. Enhanced expression of PAl-1 in visceral fat: possible contributor to vascular disease in obesity. Nat Med 1996:2:800-3

13 Charriere G, Cousin B, Arnaud E, et al. Preadipocyte conversion to macrophage. Evidence of plasticity. J Biol Chem 2003:278:9850-5.

14 Lehrke M, Lazar MA. Inflamed about obesity. Nat Med 2004; 10:126-7.

15 Shapiro L, Scherer PE. The crystal structure of a complement-lq family protein suggests an evolutionary link to tumor necrosis factor. Curr Biol 1998;8:335-8.

16 Fruebis J, Tsao TS, Javorschi S, et al. Proteolytic cleavage product of $30-\mathrm{kDa}$ adipocyte complement-related protein increases fatty acid oxidation in muscle and causes weight loss in mice. Proc Natl Acad Sci U S A 2001;13:2005-10.

17 Yamauchi T, Kamon J, Ito Y, et al. Cloning of adiponectin receptors that mediate antidiabetic metabolic effects. Nature 2003:423:762-9.

18 Chandran M, Phillips SA, Ciaraldi T, et al. Adiponectin: more than just another fat cell hormone? Diabetes Care 2003;26:2442-50.
19 Diez JJ, Iglesias P. The role of the novel adipocyte derived hormone adiponectin in human disease. Eur J Endocrinol 2003;148:293-300.

20 Yamauchi T, Kamon J, Minokoshi Y, et al Adiponectin stimulates glucose utilization and fatty acid oxidation by activating AMP-activated protein kinase. Nat Med 2002;8:1288-95.

21 Ouchi N, Kihara S, Funahashi T, et al. Obesity, adiponectin and vascular inflammatory disease. Curr Opin Lipidol 2003; 14:561-6.

22 Maeda N, Shimomura I, Kishida K, et al. Dietinduced insulin resistance in mice lacking adiponectin/ACRP30. Nat Med 2002:8:731-7.

23 Curat CA, Miranville A, Sengenes C, et al. From blood monocytes to adipose tissue-resident macrophages: induction of diapedesis by human mature adipocytes. Diabetes 2004;53:1 285-92.

24 Ouchi N, Kihara S, Arita Y, et al. Novel modulator for endothelial adhesion molecules: adipocyte-derived plasma protein adiponectin Circulation 1999:100:2473-6.

25 Ouchi N, Kihara S, Arita Y, et al. Adiponectin, adipocyte-derived plasma protein, inhibits endothelial NF- $\kappa B$ signaling through $c$ AMPdependent pathways. Circulation 2000;102:1296-301.

26 Yamamoto K, Kiyohara T, Murayama Y, et al Production of adiponectin, an anti-inflammatory protein, in mesenteric adipose tissue in Crohn's disease. Gut 2005:54:789-96.

27 Zhang B, Berger J, Hu E, et al. Negative regulation of peroxisome proliferator activated receptor $\gamma$ gene expression contributes to the antiadipogenic effects of tumor necrosis factor- $\alpha$. Mol Endocrinol 1996;10:1457-66

28 Rosenbaum S, Greenberg A. The short- and long term effects tumor necrosis factor-alpha and BRL49653 on peroxisome proliferator-activated receptor (PPAR) gamma 2 gene expression and other adipocyte genes. Mol Endocrinol 1998; 12:1150-60

29 Levine JA, Jensen MD, Eberhardt NL, et al. Adipocyte macrophage colony-stimulating factor is a mediator of adipose tissue growth. J Clin Invest 1998; 101:1557-64.

30 Okuno A, Tamemoto H, Tobe K, et al. Troglitazone increases the number of small adipocytes without the change in white adipose tissue mass in obese Zucker rats. J Clin Invest 1998; 101:1354-61.

31 Chinetti G, Fruchart JC, Staels B. Peroxisome proliferator-activated receptors (PPARs): Nuclear receptors at the crossroads between lipid metabolism and inflammation. Inflamm Res 2000;49:497-505

32 Dubuquoy L, Dharancy S, Nutten S, et al. Role of peroxisome proliferator-activated receptor $\gamma$ and retinoid $X$ receptor heterodimer in hepatogastroenterological diseases. Lance 2002:360:1410-18.
33 Wada K, Nakajima A, Blumberg RS. PPAR $\gamma$ and inflammatory bowel disease: a new therapeutic target for ulcerative colitis and Crohn's disease. Trends Mol Med 2001;7:329-31.

34 Lewis JD, Lichtenstein GR, Stein RB, et al. An open-label trial of the PPAR-gamma ligand rosiglitazone for active ulcerative colitis. Am J Gastroenterol 2001;96:3323-8.

35 Desreumaux $\mathbf{P}$, Dubuquoy L, Nutten $\mathrm{S}$, et al. Attenuation of colon inflammation through activators of retinoid $X$ receptor (RXR)/ peroxisome proliferator-activated receptor $\gamma$ (PPAR $\gamma$ ) heterodimer: a basis for new therapeutic strategies. J Exp Med 2001;193:827-38.

36 Van Deventer SJ. Tumor necrosis factor and Crohn's disease. Gut 1997;40:443-8.

37 Graham MF, Bryson GR, Diegelmann RF. Transforming growth factor beta-1 selectively augments collagen synthesis by human intestinal smooth muscle cells. Gastroenterology 1990;99:447-53.

38 Halloran BG, Prorok GD, So BJ, et al. Transforming growth factor-beta 1 inhibits human arterial smooth muscle cell proliferation in a growth-rate-dependent manner. Am J Surg 1995; 170: 193-7.

39 Murch SH, Braegger CP, Walker-Smith JA, et al. Location of tumor necrosis factor alpha by immunohistochemistry in chronic inflammatory bowel disease Gut 1993;34:1705-9.

40 Desreumaux P, Ernst O, Geboes K, et al. Inflammatory alterations in mesenteric adipose tissue in Crohn's disease. Gastroenterolgoy 1999:117:73-81.

41 Barbier M, Vidal H, Desreumaux $P$, et al. Overexpression of leptin mRNA in mesenteric adipose tissue in inflammatory bowel diseaseas. Gastroenterol Clin Biol 2003;27:987-91.

42 Levine JA, Jensen MD, Eberhardt NL, et al. Adipocyte macrophage colony-stimulating factor is a mediator of adipose tissue growth. J Clin Invest 1998;101:1557-64.

43 Xu H, Banres GT, Yang Q, et al. Chronic inflammation in fat plays a crucial role in the development of obesity-related insulin resistance. J Clin Invest 2003;1 12:1821-30.

44 Weisberg SP, McCann D, Desai M, et al. Obesity is associated with macrophage accumulation in adipose tissue. J Clin Invest 2003;1 12:1796-808.

45 Curat CA, Miranville A, Sengenes C, et al. From blood monocytes to adipose tissue-resident macrophages: induction of diapedesis by human mature adipocytes. Diabetes 2004;53:1285-92.

46 Sartipy P, Loskutoff DJ. Monocyte chemoattractant protein-1 in obesity and insulin resistance. Proc Natl Acad Sci U S A 2003;100:7265-70.

47 Robker RL, Collins RG, Beaudet $A L$, et al. Leukocyte migration in adipose tissue of mice nul for ICAM and $\mathrm{Mac}^{-1}$ adhesion receptors. Obes Res 2004; 12:936-40.

\section{Are we studying the correct state of the stellate cell to elucidate mechanisms of chronic pancreatitis?}

\section{S J Pandol}

\section{Important insights into the states of pancreatic stellate cells and their relation to the disease conditions of the pancreas}

endocrine insufficiency and a severe chronic pain syndrome. Although elucidation of the mechanisms underlying chronic pancreatitis are incomplete, considerable progress has been made in our understanding of the fibrosis process as a result of identification and characterisation of pancreatic stellate cells (PSCs) starting in $1997 .^{1-3}$ Studies with these cells suggest that they play a key role in chronic pancreatitis in a manner analogous to hepatic stellate cells and hepatic fibrosis ${ }^{4}$

In common with liver fibrosis and hepatic stellate cells there is increasing evidence demonstrating a central role for PSCs in pancreatic fibrosis and chronic pancreatitis. In the normal pancreas, quiescent PSCs are identified using 
antibodies to desmin, a cytoskeletal protein and specific PSC marker. ${ }^{1}$ They are present in the periacinar space with long cytoplasmic processes encircling the base of the acinus. Similar to hepatic stellate cells in their quiescent state, PSCs store significant amounts of vitamin A as lipid droplets in their cytoplasm.

There is general acceptance that during pancreatic injury PSCs are activated in a manner similar to hepatic stellate cells. Activation consists of processes of transformation to a myofibroblastic phenotype with loss of vitamin A stores and expression of the cytoskeletal protein $\alpha$ smooth muscle actin ( $\alpha$-SMA); production and secretion of large amounts of extracellular matrix proteins, including collagen, fibronectin, and laminin. ${ }^{6}$ Activation can be mediated by cytokines such as transforming growth factor $\beta$ and platelet derived growth factor. ${ }^{2}$ These agents can be produced and secreted by pancreatic parenchymal cells, inflammatory cells, and PSCs themselves. ${ }^{78}$ These effects of the stellate cells to produce growth factors and inflammatory mediators can be responsible for autocrine mediated proliferation and activation of stellate cells as well as for the chronic inflammatory response in chronic pancreatitis. These responses of the stellate cell may account for the continued progression of chronic pancreatitis processes in individuals, even after cessation of alcohol abuse.

Support for PSCs in the pathogenesis of pancreatic fibrosis in chronic pancreatitis comes from investigations of pancreatic tissue in patients with chronic pancreatitis and from animal experimental models. ${ }^{910}$ The results demonstrated that in both situations PSCs, as identified by $\alpha$-SMA actin antibodies, are present in fibrotic areas, as determined by Sirius red or collagen I antibody staining. Furthermore, $\alpha$-SMA positive cells also stained by in situ hybridisation with a probe for collagen $\alpha 1$ mRNA, indicating that these cells are an important source of collagen in fibrotic areas. Such findings provide strong evidence for PSCs in the mechanism of pancreatic fibrosis.

Because of the key role for the stellate cell in the mechanism of these chronic inflammatory/fibrosing states, elucidation of the mechanisms of its transformation is necessary in order to develop treatment strategies. One of the major dilemmas in the research of stellate cells is the fact that they undergo transformation to an activated phenotype after isolation during in vitro culture. Do cultured stellate cells undergoing transformation in vitro represent the state of the stellate cell in chronic fibrosing diseases of the pancreas? Is this the correct state of the PSC to study for determining its role in chronic fibrosing disease? These questions have not been adequately addressed.

The paper by Manapov and colleagues ${ }^{11}$ in this issue of Gut provides important insights into the states of PSCs and their relation to the disease conditions of the pancreas (see page 814). The key findings in this study are that stellate cells undergoing activation in culture can either die by apoptosis or convert to "fibroblasts" that are resistant to apoptosis. Furthermore, the authors found that the phenotype of activated stellate cells susceptible to apoptosis occurs in an experimental model of pancreatitis that resolves with return of the pancreas to normal after removal of the injury. On the other hand, cells with the "fibroblast" phenotype are present in an experimental model of progressive pancreatic fibrosis. The authors demonstrated that in the activated stellate cell susceptible to apoptosis, a cell cycle inhibitory protein p $21^{\mathrm{Cipl} / \mathrm{WAFl}}$ is present in the nucleus. With conversion of the stellate cell to the "fibroblastic" state, p21 $1^{\mathrm{Cipl} / \mathrm{WAF} 1}$ translocates to the cytoplasm. Cytoplasmic $\mathrm{p} 21^{\mathrm{Cipl} / \mathrm{WAF} 1}$ binds to and inhibits activities of Rho kinase 2 and apoptosis signal regulating kinase 1 , resulting in decreased proliferation signals and apoptosis resistance.

Of interest, $\alpha$-SMA, a marker of activation in stellate cells, is reduced in expression in "fibroblastic" cells. Thus although $\alpha$-SMA is a frequently used measure of the activated state of stellate cells, it may not identify the cell population responsible for fibrosis. Findings that non- $\alpha$-SMA expressing fibroblastic cells are responsible for both pancreatic and hepatic fibrosis have been reported in experimental models of pancreatitis and human cirrhosis. ${ }^{12}{ }^{13}$

What is the significance of the findings related to $\mathrm{p} 21^{\mathrm{Cipl} / \mathrm{WAF}}$ ? This cell cycle inhibitory protein may represent a central regulator of terminal differentiation, as shown in monocytic and neural cells. $^{14} 15$ In these cases, p2 $1^{\text {Cipl/WAF1 }}$ expression with localisation in the nucleus leads to cell cycle arrest followed by its translocation to the cytoplasm where it is associated with terminal differentiation. Translocation of $\mathrm{p} 21^{\mathrm{Cip} 1 / \mathrm{WAF} 1}$ to the cytoplasm in these cells also results in apoptosis resistance, as occurred in the stellate cells.

Considering the similarities in the pattern of changes in $\mathrm{p} 21^{\mathrm{Cipl} / \mathrm{WAF}}$ associated with differentiation in monocytic cells, neuronal cells, and stellate cells, the results in the report by Manapov and colleagues ${ }^{11}$ provides a basis to propose that the "fibroblastic" phenotype of the stellate cell is a terminally differentiated state. As described in this report and previous ones, ${ }^{13}{ }^{14}$ this phenotype expresses little or no $\alpha$-SMA and is resistant to apoptosis. Furthermore, it is very likely, as proposed by Manapov et al, that p21 $1^{\text {CipI/WAFI }}$ plays a central role in proliferation, apoptosis, and differentiation of the stellate cell. The mechanisms underlying regulation of $\mathrm{p} 2 \mathrm{l}^{\mathrm{Cip} 1 / \mathrm{WAF} 1}$ expression and translocation are unknown. Establishing the underlying mechanism for one or both of these processes may lead to potential strategies for the treatment of fibrosing diseases.

Gut 2005;54:744-745.

doi: $10.1136 /$ gut.2004.054080

Correspondence to: Dr S Pandol, UCLA Department of Medicine, West Los Angeles VAGLAHS, 11301 Wilshire Blvd., Building 258, Room 340, Los Angeles, CA 90073, USA; stephen.pandol@med.va.gov

Conflict of interest: None declared.

\section{REFERENCES}

1 Apte MV, Haber PS, Applegate TL, et al. Periacinar stellate shaped cells in rat pancreas: identification, isolation, and culture. Gut 1998;43:128-33.

2 Bachem MG, Schneider E, Gross H, et al. Identification, culture, and characterization of pancreatic stellate cells in rats and humans. Gastroenterology 1998;115:421-32.

3 Saotome T, Inove H, Fujimiya M, et al. Morphological and immunocytochemical identification of periacinar fibroblast-like cells derived from human pancreatic acini. Pancreas 1997; 14:373-82.

4 Li D, Friedman SL. Liver fibrogenesis and the role of hepatic stellate cells: new insights and prospects for therapy. J Gastroenterol Hepatol 1999; 14:618-33.

5 Friedman SL. Seminars in medicine of the Beth Israel Hospital, Boston. The cellular basis of hepatic fibrosis. Mechanisms and treatment strategies. N Engl J Med 1993;328:1828-35.

6 Mews $P$, Phillips $P$, Fahmy $R$, et al. Pancreatic stellate cells respond to inflammatory cytokines: potential role in chronic pancreatitis. Gut 2002;50:535-41.

7 Masamune A, Kikuta K, Satoh M, et al. Alcohol activates activator protein-1 and mitogenactivated protein kinases in rat pancreatic stellate cells. J Pharmacol Exp Ther 2002;302:36-42.

8 Masamune A, Kikuta K, Suzuki N, et al. A c-Jun $\mathrm{N}$-terminal kinase inhibitor SP600125 blocks activation of pancreatic stellate cells. J Pharmacol Exp Ther 2004;310:520-7.

9 Haber PS, Keogh GW, Apte MV, et al. Activation of pancreatic stellate cells in human and experimental pancreatic fibrosis. Am J Pathol 1999; 155:1087-95

10 Casini A, Galli A, Pignalosa P, et al. Collagen type I synthesized by pancreatic periacinar stellate cells (PSC) co-localizes with lipid peroxidation-derived aldehydes in chronic alcoholic pancreatitis. J Pathol 2000;192:81-9.

11 Manapov F, Muller P, Rychly J. Translocation of

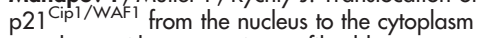
correlates with pancreatic myofibroblast to fibroblast cell conversion. Gut 2005;54:814-22

12 Tashiro M, Nakamura H, Taguchi M, et al. Oleic acid-induced pancreatitis alters expression of transforming growth factor-betal and extracellular matrix components in rats. Pancreas 2003; 26: 197-204

13 Levy MT, McCaughan GW, Marinos G, et al. Intrahepatic expression of the hepatic stellate cell marker fibroblast activation protein correlates with the degree of fibrosis in hepatitis $C$ virus infection. Liver 2002;22:93-101.

14 Asada M, Yamada T, Ichijo H, et al. Apoptosis inhibitory activity of cytoplasmic p21(Cipl) WAFI) in monocytic differentiation. EMBO J 1999; 18:1223-34.

15 Tanaka H, Yamashita T, Asada M, et al. Cytoplasmic p21(Cipl/WAF1) regulates neurite remodeling by inhibiting Rho-kinase activity. J Cell Biol 2002;158:321-9. 